\title{
Endoscopic removal of a migrated stent in the gallbladder
}

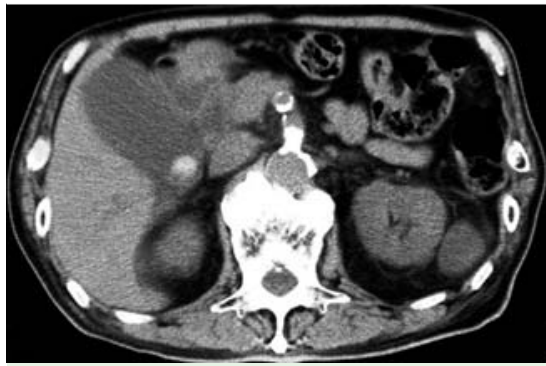

Fig. 1 Abdominal computed tomography (CT) image showing evidence of acute cholecystitis.

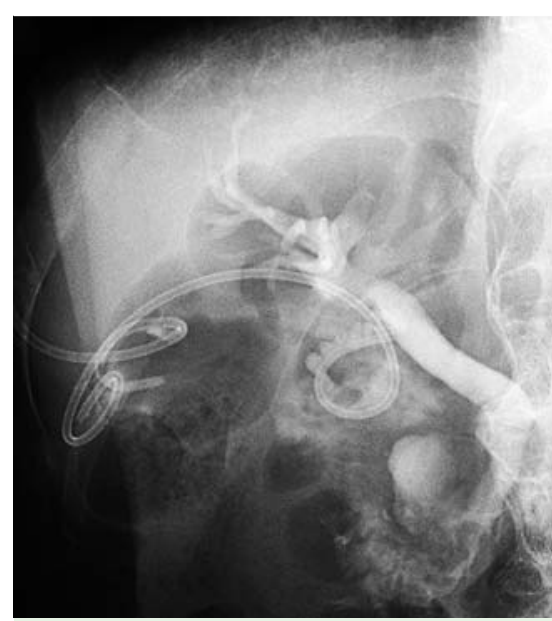

Fig. 2 The incorrectly positioned bilateral pigtail plastic stent.

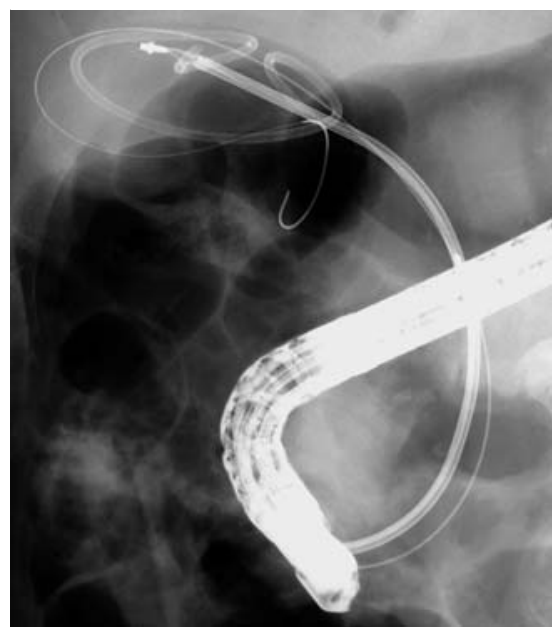

Fig. 3 Fluoroscopic view showing an unsuccessful attempt being made to retrieve the stent using a basket.
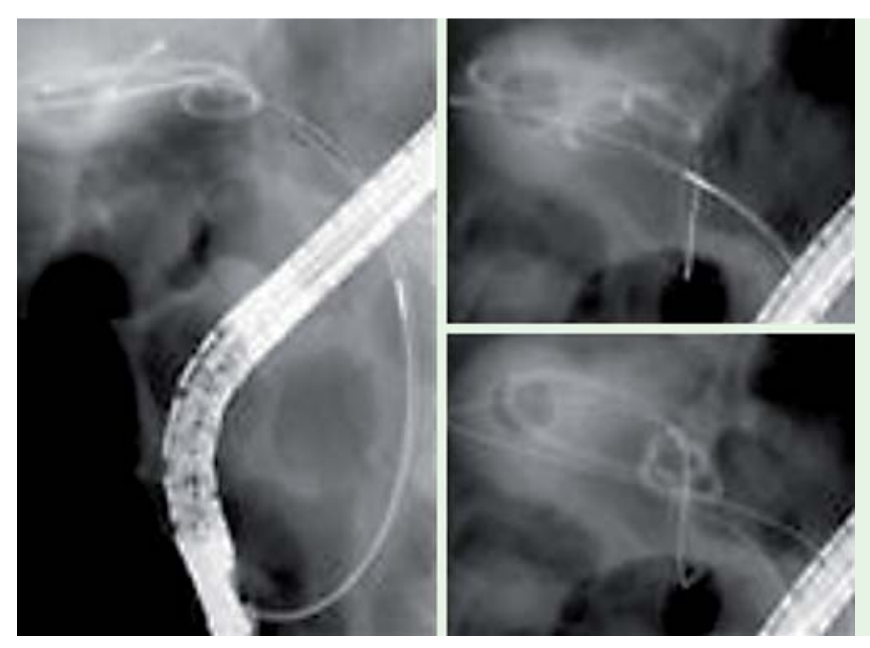

Fig.4 A polypectomy snare consisting of a single looped wire that can be used to easily grip the tip of the stent.

An 84-year old man was admitted to our hospital with fever and abdominal pain. An abdominal computed tomography (CT) scan revealed evidence of acute cholecystitis ( Fig.1). Percutaneous transhepatic gallbladder drainage was performed and his symptoms improved; however, cholecystectomy could not be performed because the patient's heart function was too poor.

To prevent him developing recurrent cholecystitis, we tried to perform endoscopic transpapillary gallbladder stenting [1 - 3], but owing to a crooked cystic duct, a bilateral pig-tail plastic stent $(6 \mathrm{Fr}, 10 \mathrm{~cm})$ was placed in an incorrect position ( $\bullet$ Fig. 2 ).

We initially tried to retrieve the migrated stent using several types of basket; however, all of these attempts failed (ه Fig.3). Finally, we tried to move the stent using a polypectomy snare, which consists of a single looped wire that can easily grip the tip of the stent ( $\mathbf{F i g . 4}$ ). Using this snare, we succeeded in smoothly placing the stent in the correct position (๑ Fig. 5 and $\odot$ Fig. 6 ).

Stent migration into the gallbladder is a rare but important condition for endoscopists.

Endoscopy_UCTN_Code_TTT_1AR_2AZ

Competing interests: None
Tomonori Ida ${ }^{1}$, Masahiko Inamori ${ }^{2,3}$, Jun Hamanaka', Hideyuki Chiba', Akihiko Kusakabe², Taiki Morohashi ${ }^{1}$, Atsushi Nakajima², Shin Maeda²,

\section{Toru Goto ${ }^{1}$}

${ }^{1}$ Department of Gastroenterology, Omori Red Cross Hospital, Tokyo, Japan

${ }^{2}$ Gastroenterology Division, Yokohama

City University Hospital, Yokohama, Japan

${ }^{3}$ Office of Postgraduate Medical Education, Yokohama City University Hospital, Yokohama, Japan

\section{References}

1 Conway JD, Russo MW, Shrestha R. Endoscopic stent insertion into the gallbladder for symptomatic gallbladder disease in patients with end stage liver disease. Gastrointest Endosc 2005; 61: 32-36

2 Schlenker C, Trotter JF, Shah RJ et al. Endoscopic gallbladder stent placement for treatment of symptomatic cholelithiasis in patients with end-stage liver disease. Am J Gastroenterol 2006; 101: 278-283

3 Lee TH, Park DH, Lee SS et al. Outcome of endoscopic transpapillary gallbladder stenting for symptomatic gallbladder disease: a multicenter prospective follow-up study. Endoscopy 2011; 43: 702 - 708 


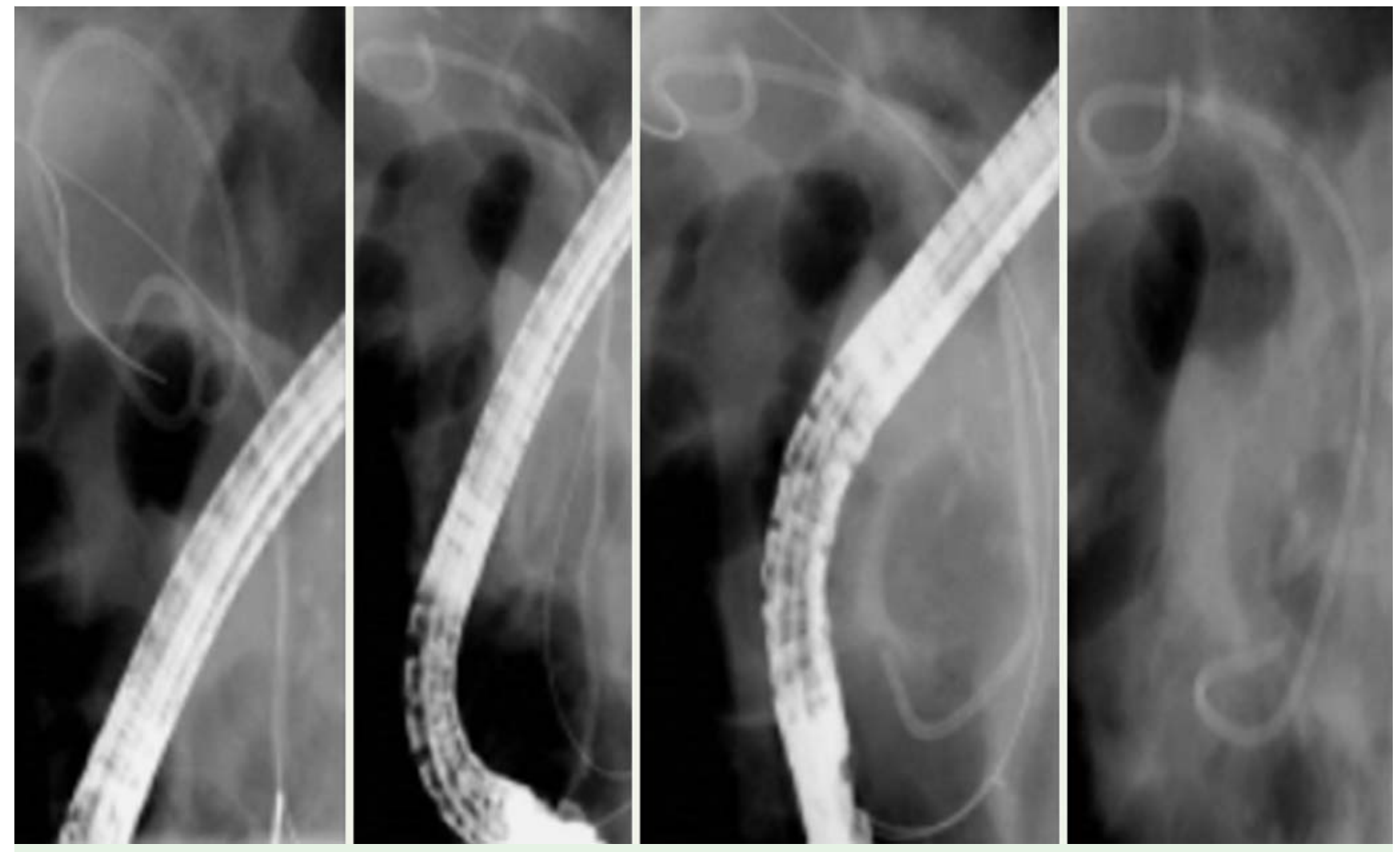

Fig. 5 Fluoroscopic views showing the stent being successfully moved into the correct position.

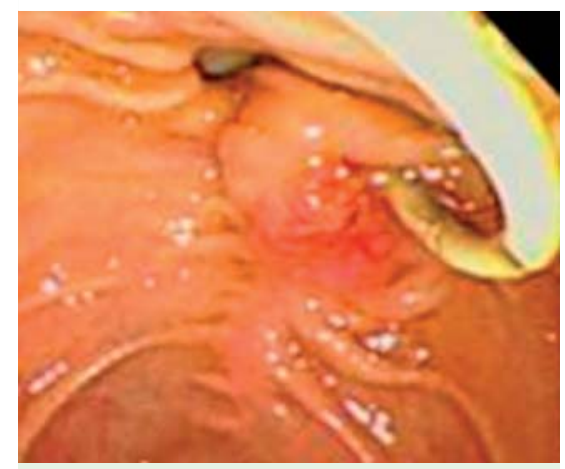

\section{Bibliography}

DOI http://dx.doi.org/

10.1055/s-0034-1377634

Endoscopy 2014; 46: E539-E540

(c) Georg Thieme Verlag KG

Stuttgart · New York

ISSN 0013-726X

\author{
Corresponding author \\ Masahiko Inamori, MD \\ Yokohama City University Hospital, \\ Gastroenterology Division \\ 3-9, Fuku-ura, Kanazawaku \\ Yokohama \\ Kanagawa 236-0004 \\ Japan \\ Fax: +81-45-7843546 \\ inamorim@med.yokohama-cu.ac.jp
}

Fig. 6 Endoscopic view of the papilla of Vater and one end of the stent after it had been successfully repositioned. 